\title{
Nerve conduction during Wallerian degeneration in the baboon
}

\author{
R. W. GILLIATT AND R. J. HJORTH
}

From The Institute of Neurology, Queen Square, London

SUMMARY Conduction in the lateral popliteal nerve of the baboon was studied during the course of Wallerian degeneration. Six nerves were examined. In each case the muscle response to nerve stimulation and the ascending nerve action potential were recorded daily until the nerve became inexcitable. The muscle response to nerve stimulation disappeared after four to five days, but ascending nerve action potentials could be recorded for a further two to three days. There was no change in maximal motor conduction velocity or in distal latency until the muscle response to nerve stimulation was severely reduced in amplitude. At this stage there was a consistent increase in distal latency, sometimes associated with a mild reduction in maximal motor velocity in the leg. There was no change in the velocity of ascending nerve action potentials. Histological studies confirmed the presence of degeneration in the terminal parts of the intramuscular nerve fibres at a time when the proximal parts of the same fibres were relatively normal.

Conduction in peripheral nerves during Wallerian degeneration has been studied in small animals such as rats and guinea-pigs (Gutmann and Holubáŕ, 1950, 1952; Kaeser and Lambert, 1962) and in cats and dogs (Rosenblueth and Dempsey, 1939; Erlanger and Schoepfle, 1946) but surprisingly little information is available for primates. In eight patients with traumatic nerve transections Landau (1953) stimulated the peripheral portion of the cut nerves and recorded the time after injury at which the muscle response to nerve stimulation disappeared. No electrophysiological records of response amplitude or latency were made. Gilliatt and Taylor (1959) studied the response of the facial muscles to nerve stimulation in three patients after surgical division of the nerve for the relief of hemifacial spasm. Response amplitude and latency were recorded but, in view of the hemifacial spasm, these nerves cannot be regarded as entirely normal before section; indeed one of them had been crushed in a previous surgical attempt to relieve the spasm.

In sub-human primates even fewer observations are available. Landau included observations of one macaque in his paper on human nerve lesions. The only other relevant observation we have found in the literature is that of Heinbecker, Bishop, and O'Leary (1932) on excised nerves from a macaque two days after section.
Recent work on toxic neuropathy in the baboon has renewed interest in the time-course of Wallerian degeneration. In the present experiments conduction in the lateral popliteal nerve of the baboon has been studied on successive days after nerve section and the results correlated with the anatomical changes.

\section{METHODS}

The experiments were carried out on sexually mature female baboons (Papio papio). The lateral porliteal nerve was divided under aseptic conditions in the lower thigh. The site of division was subsequently checked at necropsy; in each case it was 5 to $10 \mathrm{~cm}$ proximal to the site of stimulation at the neck of the fibula. Anaesthesia for nerve section and for electrophysiological studies was provided by intramuscular phencyclidine hydrochloride and promazine, supplemented by intravenous pentobarbitone. This form of anaesthesia did not give rise to side-effects when repeated daily in individual animals for six to nine days.

For the measurement of maximal motor conduction velocity, supramaximal shocks were delivered to the lateral popliteal nerve at the neck of the fibula, and to the anterior tibial nerve on the dorsum of the ankle, muscle action potentials being recorded from extensor digitorum brevis through belly-tendon electrodes. Stimulating and recording electrodes were stainless steel needles placed subcutaneously as described by Hopkins and Gilliatt (1971). After 
the muscle records had been made, ascending action potentials were recorded from the lateral popliteal nerve at the neck of the fibula with stimulation of the anterior tibial nerve at the ankle. Details of the technique are described by Hopkins and Gilliatt (1971). The intramuscular temperature in the tibialis anterior muscle was recorded at the beginning and end of each session and varied between $35^{\circ}$ and $38^{\circ} \mathrm{C}$.

For histological studies, specimens of muscle and nerve were taken shortly after the animals were killed, and were fixed to cards. Flemming's solution was used to fix nerve for subsequent staining with Kultschitsky's haematoxylin (Gutmann and Sanders, 1943) but for all other stains the fixative was $10 \%$ neutral formalin. Specimens of the nerve were stained with osmium tetroxide in preparation for the examination of single teased fibres (Thomas, 1955), while others were embedded in paraffin and stained by the Holmes silver method, combined with cresyl violet and luxol fast blue (McDonald, 1963). Some specimens of muscle were embedded in gelatine and thick $(50-100 \mu)$ sections were cut which were stained by Koelle's cholinesterase method for endplates (Gomori, 1952). In order to show the intramuscular nerve fibres in the same sections, additional myelin staining with Sudan black B (Cavanagh, Passingham, and Vogt, 1964) or axon staining with a modified Bielschowsky silver technique was performed before mounting in a water-based mountant.

\section{RESULTS}

Electrophysiological observations before and after nerve section were made on six nerves in four animals. In each case recordings were made daily until conduction failed completely.

Tracings of muscle action potentials from one animal are shown in Fig. 1. It can be seen that the amplitude of the muscle action potentials had

TABLE 1

AMPLITUDE OF NEGATIVE DEFLECTION OF EVOKED MUSCLE ACTION POTENTIALS WITH NERVE STIMULATION AT KNEE AND ANKLE. MEAN VALUES ON SUCCESSIVE DAYS AFTER NERVE SECTION IN THE THIGH

\begin{tabular}{lcccccc}
\hline & Pre-op & \multicolumn{5}{c}{ Days after nerve section } \\
& & 1 & 2 & 3 & 4 & 5 \\
\hline $\begin{array}{l}\text { Number of nerves } \\
\begin{array}{l}\text { Mean response amplitude } \\
\text { with knee stimulation } \\
(m V)\end{array}\end{array}$ & 6 & 6 & 6 & 6 & 5 & 1 \\
$\begin{array}{l}\text { Mean response amplitude } \\
\text { with ankle stimulation } \\
(m V)\end{array}$ & 15.5 & 14.2 & 10.6 & 6.1 & 1.0 & 1.3 \\
$\begin{array}{l}\text { Ratio knee } \\
\text { ankle }\end{array}$ & 1.01 & 13.9 & 11.3 & 5.7 & 1.2 & 1.3 \\
\hline
\end{tabular}

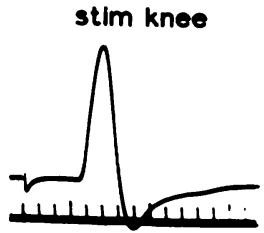

stim ankle
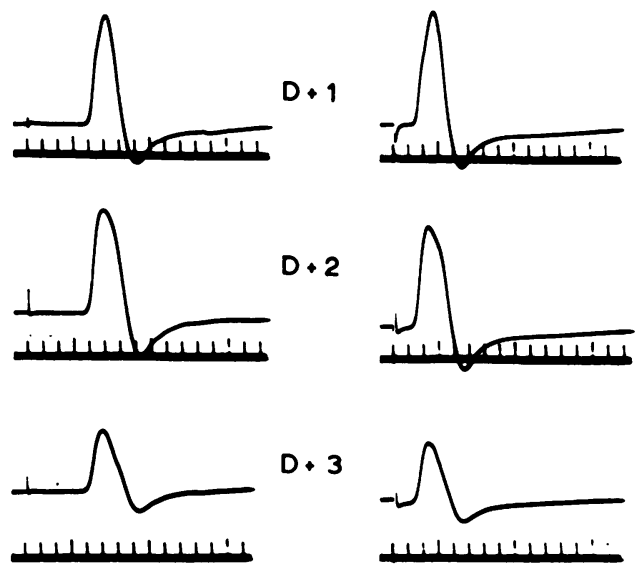

$D+3$
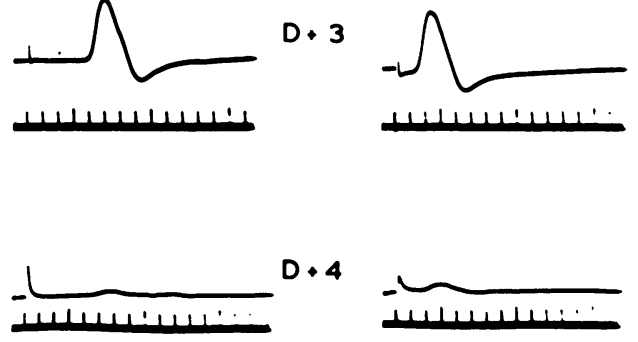

$D+4$
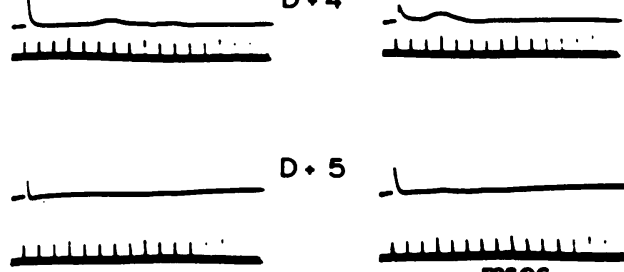

$0 \cdot 5$

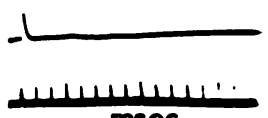

msec

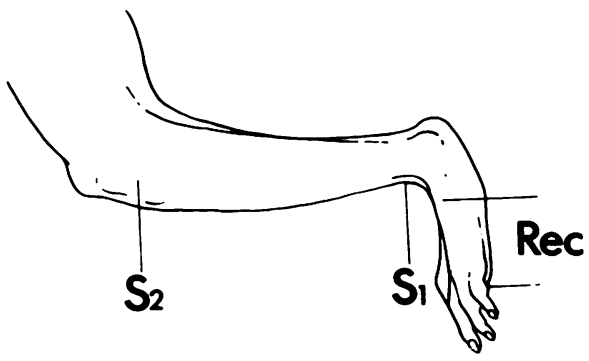

FIG. 1. Nerve B2R. Muscle action potentials evoked by nerve stimulation on successive days after nerve section in the thigh. The position of stimulating and recording electrodes is shown below.

fallen by only $21 \%$ after two days but thereafter the change was more rapid, the amplitude being reduced to approximately $3 \%$ of the control 


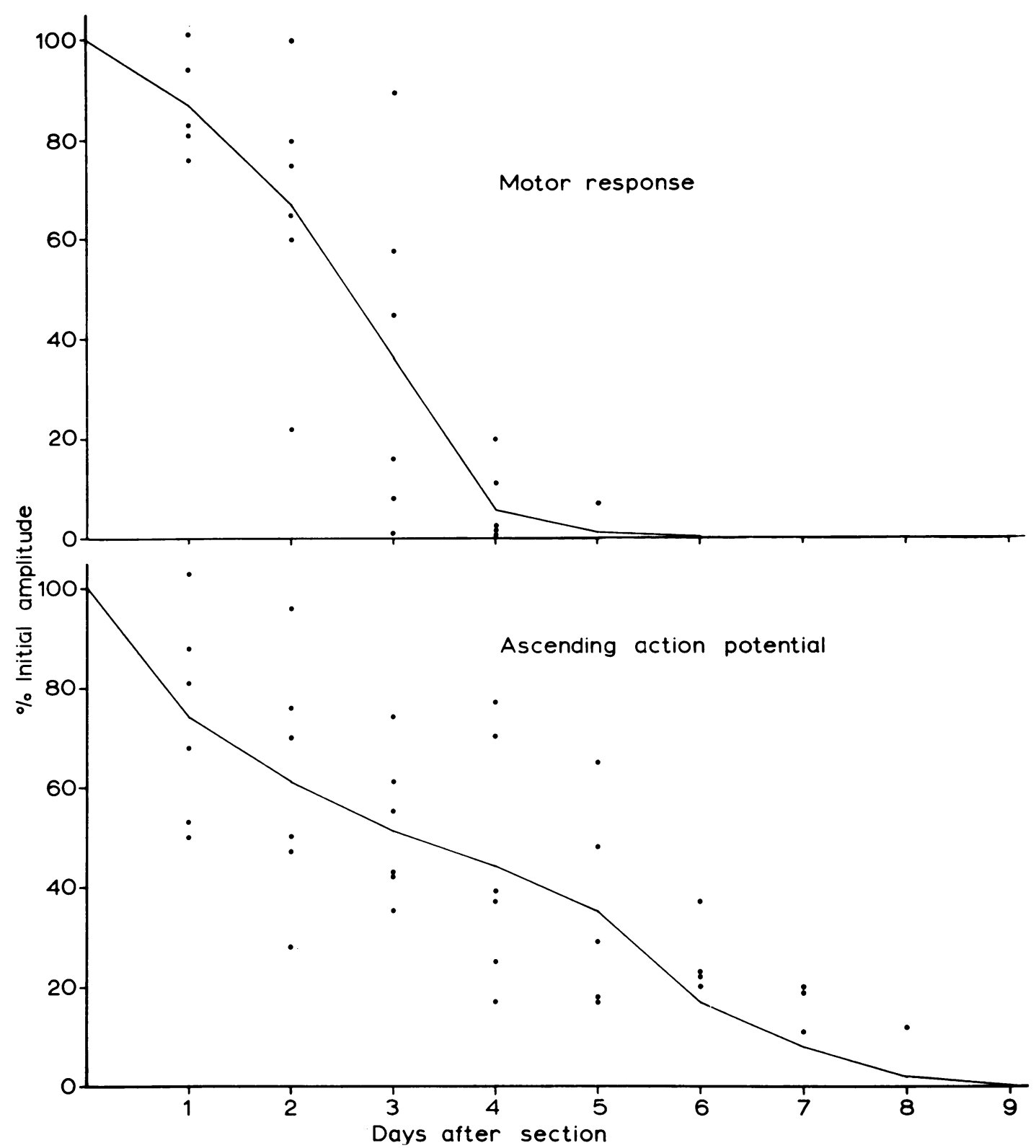

FIG. 2. Graphs to show the decline in amplitude of the muscle response to nerve stimulation (above) and of the ascending nerve action potential (below) after nerve section. Mean values for the six nerves are shown by the continuous lines.

value after four days. No muscle response to nerve stimulation was obtained after this time. Results for all six nerves are shown in Fig. 2 from which it can be seen that a muscle response was obtainable after five days in one case but not in the others. No muscle response was obtained after six days in any animal.

The values for muscle action potential ampli- tude shown in Fig. 2 are those obtained by nerve stimulation at the ankle. In Table 1 a comparison is made with the amplitude of the muscle response obtained by stimulation at the knee. It can be seen that after nerve section the reduction in muscle action potential amplitude was similar for knee and ankle stimulation. From this it may be assumed that the failure of conduction was 

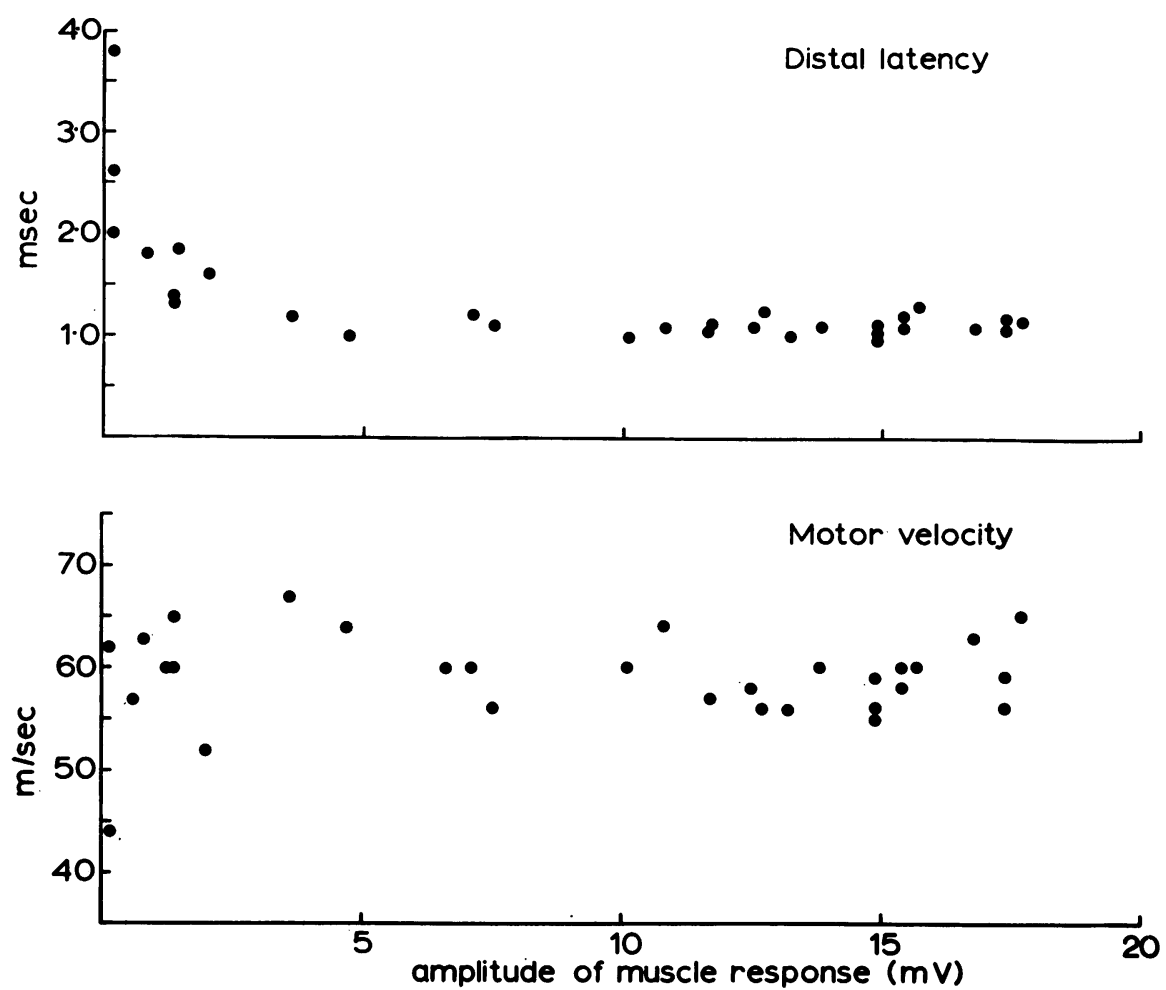

FIG. 3. Maximal motor velocity and distal latency on successive days after nerve section (six nerves). Values are related to the amplitude of the muscle response in each case.

occurring at a point distal to the stimulating electrode at the ankle.

The changes in maximal motor conduction velocity and distal latency after nerve section are shown in Fig. 3. It can be seen that velocity and distal latency remained unchanged until response amplitude was greatly reduced. With values for response amplitude of $2 \mathrm{mV}$ or less, maximal velocity was sometimes reduced and distal latency was increased in every case, the highest value $(3.8 \mathrm{msec})$ being seen in nerve $4 \mathrm{~L}$, four days after section. On this occasion, response amplitude was only $0.1 \mathrm{mV}$ and conduction velocity was $44 \mathrm{~m} / \mathrm{sec}$. Initial values for response amplitude, conduction velocity, and distal latency in this nerve were $18 \mathrm{mV}, 58 \mathrm{~m} / \mathrm{sec}$, and $1 \cdot 1$ msec respectively.

The effects of nerve section on ascending action potentials are illustrated by the tracings shown in Fig. 4, and results for the six nerves are shown graphically in Fig. 2. It can be seen that ascending nerve action potentials (which include antidromic impulses in motor fibres) persisted longer after nerve section than the muscle

TABLE 2

MEAN VELOCITY OF ASCENDING NERVE ACTION POTENTIALS IN SIX NERVES AFTER SECTION, EXPRESSED AS PERCENTAGE OF PREOPERATIVE VELOCITY

\begin{tabular}{|c|c|c|c|c|c|c|c|c|}
\hline & \multicolumn{8}{|c|}{ Days after nerve section } \\
\hline & 1 & 2 & 3 & 4 & 5 & 6 & 7 & 8 \\
\hline $\begin{array}{l}\text { Number of observations } \\
\text { Mean velocity and S.E. }\end{array}$ & $\begin{array}{c}6 \\
98 \\
(2 \cdot 4)\end{array}$ & $\begin{array}{c}6 \\
101 \\
(3 \cdot 4)\end{array}$ & $\begin{array}{r}6 \\
102 \\
(3 \cdot 0)\end{array}$ & $\begin{array}{c}6 \\
97 \\
(6 \cdot 0)\end{array}$ & $\begin{array}{c}5 \\
97 \\
(4 \cdot 6)\end{array}$ & $\begin{array}{c}4 \\
94 \\
(4 \cdot 9)\end{array}$ & $\begin{array}{c}3 \\
98 \\
(4 \cdot 7)\end{array}$ & $\begin{array}{r}1 \\
98\end{array}$ \\
\hline
\end{tabular}



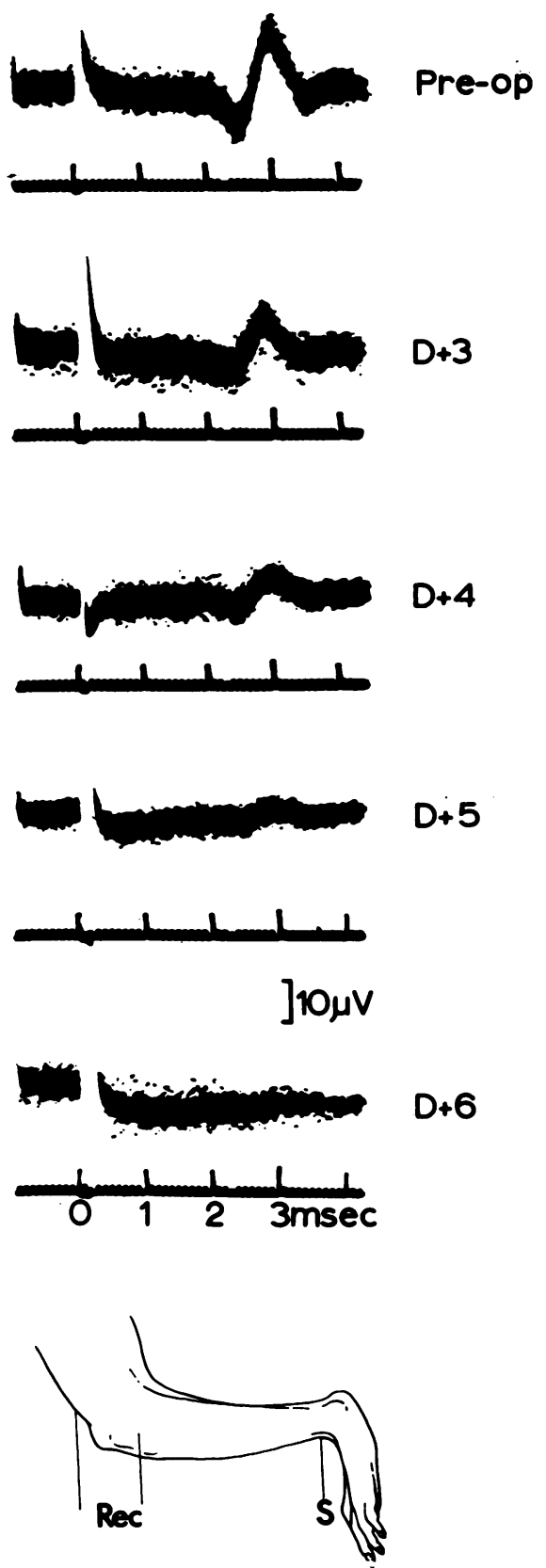

FIG. 4. Nerve B4R. Ascending action potentials recorded from the lateral popliteal nerve at the knee after section of the nerve in the thigh. Twenty-five faint traces superimposed in each record.

responses to motor nerve stimulation. The significance of this is discussed in a subsequent section. It can also be seen from the tracings in Fig. 4 that there was no change in the latency of the ascending action potentials during Wallerian degeneration. In some of the animals a low voltage deflection was seen preceding the main potential change. This early component was originally described by Hopkins (1968) and considered to be due to impulses in a group of low threshold, high-velocity, afferent fibres. In the present study, this initial component made latency measurement difficult. Before nerve section its amplitude was only $1-3 \mu \mathrm{V}$, and when this was further reduced during Wallerian degeneration, accurate measurement became impossible. However, velocity calculated from the latency measured to the foot of the main deflection of the ascending action potential showed no significant change after nerve section in the six nerves examined (Table 2).

For comparison with the electrophysiological results, nerves were taken for histology from two additional animals three and six days after section. Control nerves were also examined. Three days after section the nerve trunk in the leg showed only minor changes. Longitudinal sections stained by the Holmes silver method and counterstained by luxol fast blue and cresyl violet were normal save for occasional vacuoles in the myelin. Individual teased fibres showed slight irregularity of the contour of the myelin, particularly in the paranodal regions, but the

\section{TABLE 3}

TIME TO CONDUCTION FAILURE DISTAL TO NERVE SECTION. RESULTS FOR NERVE TRUNK SHOWN ABOVE, AND FOR MUSCLE RESPONSE TO NERVE STIMULATION BELOW

\begin{tabular}{|c|c|c|c|}
\hline Species & Nerve & $\begin{array}{c}\text { Time to } \\
\text { failure }(h r)\end{array}$ & Authors \\
\hline $\begin{array}{l}\text { Nerve trunk } \\
\text { Rabbit }\end{array}$ & $\begin{array}{l}\text { peroneal } \\
\text { (lat. popliteal) }\end{array}$ & $71-78$ & $\begin{array}{l}\text { Gutmann and Holubár } \\
\text { (1950) }\end{array}$ \\
\hline Rat & $\begin{array}{l}\text { peroneal } \\
\text { (lat. popliteal) }\end{array}$ & $79-81$ & $\begin{array}{l}\text { Gutmann and Holubár } \\
\text { (1950) }\end{array}$ \\
\hline Guinea-pig & $\begin{array}{l}\text { peroneal } \\
\text { (lat. popliteal) }\end{array}$ & $72-82$ & $\begin{array}{l}\text { Gutmann and Holubáf } \\
\text { (1950) }\end{array}$ \\
\hline Cat & sciatic & $72-101$ & $\begin{array}{l}\text { Rosenblueth and } \\
\text { Dempsey (1939) }\end{array}$ \\
\hline Dog & phrenic & 96 & $\begin{array}{l}\text { Erlanger and Schloepfle } \\
\quad(1946)\end{array}$ \\
\hline Baboon & lateral popliteal & $120-216$ & Present series \\
\hline \multicolumn{4}{|l|}{ Nerve muscle } \\
\hline Rabbit & $\begin{array}{l}\text { peroneal } \\
\text { (lat. popliteal) }\end{array}$ & $30-32$ & $\begin{array}{l}\text { Gutmann and Holubáf } \\
\text { (1952) }\end{array}$ \\
\hline Rat & sciatic & $24-36$ & Miledi and Slater (1970) \\
\hline Guinea-pig & sciatic & $40-45$ & $\begin{array}{l}\text { Kaeser and Lambert } \\
\text { (1962) }\end{array}$ \\
\hline Cat & sciatic & $69-79$ & $\begin{array}{l}\text { Lissak, Dempsey, and } \\
\text { Rosenblueth (1939) }\end{array}$ \\
\hline Man & median ulnar* & $85-128$ & Landau (1953) \\
\hline Man & facial & $120-192$ & $\begin{array}{l}\text { Gilliatt and Taylor } \\
\text { (1959) }\end{array}$ \\
\hline Baboon & lateral popliteal & $96-144$ & Present series \\
\hline
\end{tabular}

* From observation of muscle twitch-no electrical recording. 

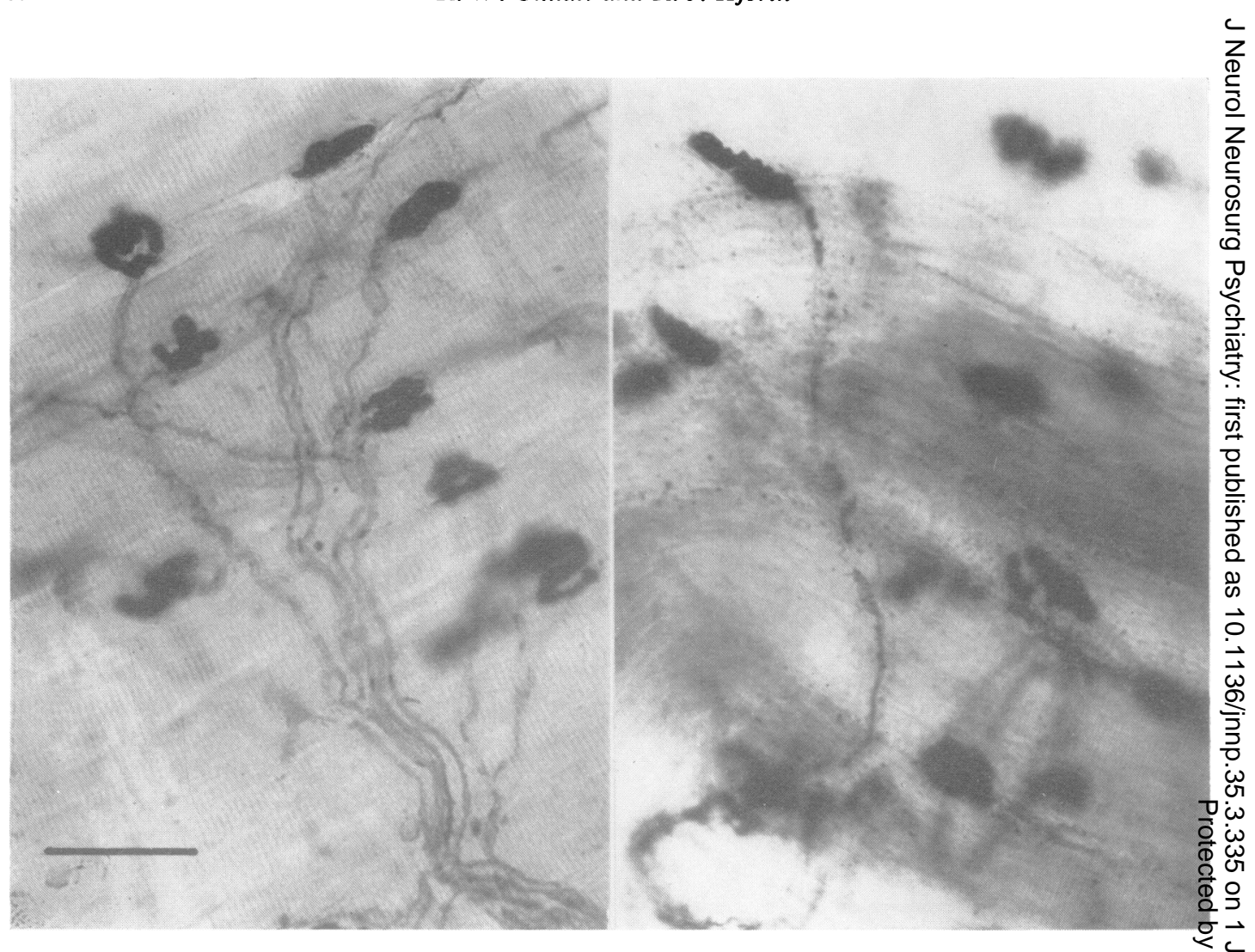

FIG. 5. Terminal nerve branches and end-plates from extensor digitorum brevis muscle of control baboon (left) and baboon killed three days after lateral popliteal nerve section in the thigh (right). Thick $(50 \mu)$ sections stained by Koelle's method followed by Sudan black B. Scale $50 \mu$.

nodes of Ranvier were not widened (cf. Causey and Palmer, 1952). In contrast to these relatively normal appearances, some of the intramuscular nerve bundles already showed fragmentation of myelin which increased as the end-plate region was approached (Fig. 5). In many cases the terminal portions of the fibres had disappeared, although the proximal parts were still visible. Six days after nerve section, loss of continuity of axons could be seen in the leg as well as in the intramuscular nerve bundles, the changes still being more marked distally. By this time the terminal portions of the intramuscular nerves had disappeared.

\section{DISCUSSION}

Previous writers have emphasized that failure of neuromuscular transmission precedes loss of conduction in the nerve trunk during Wallerian degeneration (Titeca, 1935; Lissák, Dempsey, and Rosenblueth, 1939; Birks, Katz, and Miledi,
1960). Histological studies have shown early changes in terminal nerve fibres (Gutmann and Holubár. 1952) and in the end-plates themselveso (Miledi and Slater, 1970). These observations are supported by our own findings. For example histological examination three days after section showed advanced changes in the terminap̣. branches of intramuscular nerve fibres, whereas the same fibres in the leg showed only occasiona $\vec{F}$ abnormalities. In the nerves examined electrophysiologically, ascending action potentials were present after the muscle response to nerve् stimulation had disappeared. This latter finding is unlikely to be due to the longer survival of sensory fibres than motor fibres, since others have shown that conduction failure tends to occur earlier in the former than in the lattefos (Gutmann and Holubář, 1949).

A slight reduction in conduction velocity during Wallerian degeneration has been described by previous writers (Gutmann an Holubáŕ, 1950; Kaeser and Lambert, 1962). Irø్ 
the present experiments no change in maximal motor velocity or in distal latency occurred until most of the nerve fibres had ceased to conduct impulses. At this stage distal latency had increased in all nerves and conduction velocity was mildly reduced in two. These results do not necessarily imply a velocity change in individual fibres. They could be explained by the survival of normal fibres with a relatively low velocity or a long intramuscular course. In the case of ascending nerve action potentials, the present results provide no evidence of a velocity change preceding conduction failure.

The time to conduction failure varies considerably in different species. In Table 3 our own results are compared with those of previous workers. From this it appears that the time to final failure of conduction in the lateral popliteal nerve of the baboon is substantially longer than that found in the nerve trunks of lower mammals. Neuromuscular transmission in the baboon also persists for longer than is the case in lower mammals. There is a suggestion that this time might be longer still in man (Gilliatt and Taylor, 1959) and further information on this point would be of considerable interest.

This work was supported by a grant from the Medical Research Council.

\section{REFERENCES}

Birks, R., Katz, B., and Miledi, R. (1960). Physiological and structural changes at the amphibian myoneural junction, in the course of nerve degeneration. Journal of Physiology, 150, 145-168.

Causey, G., and Palmer, E. (1952). Early changes in degenerating mammalian nerves. Proceedings of the Royal Society. Series B. 139, 597-609.

Cavanagh, J. B., Passingham, R. J., and Vogt, J. A. (1964). Staining of sensory and motor nerves in muscles with Sudan black B. Journal of Pathology and Bacteriology, 88, 89-92.

Erlanger, J., and Schoepfle, G. M. (1946). A study of nerve degeneration and regeneration. American Journal of Physiology, 147, 550-581.
Gilliatt, R. W., and Taylor, J. C. (1959). Electrical changes following section of the facial nerve. Proceedings of the Royal Society of Medicine, 52, 1080-1083.

Gomori, G. (1952). Microscopic Histochemistry. University of Chicago Press: Chicago, III.

Gutmannn, E., and Holubáŕ, J. (1949). Failure of transmission of motor and sensory nerve impulses after nerve section. Nature, 163, 328-329.

Gutmann, E., and Holubáŕ, J. (1950). The degeneration of peripheral nerve fibres. Journal of Neurology, Neurosurgery, and Psychiatry, 13, 89-105.

Gutmann, E., and Holubáŕ, J. (1952). Degenerace terminálních orgánů $\mathrm{v}$ přičně pruhovaném a hladkém svalstvu. Ceskoslovenska Fysiologie, 1, 168-175.

Gutmann, E., and Sanders, F. K. (1943). Recovery of fibre numbers and diameters in the regeneration of peripheral nerves. Journal of Physiology, 101, 489-518.

Heinbecker, P., Bishop, G. H., and O'Leary, J. L. (1932). Nerve degeneration in poliomyelitis. 3. Archives of Neurology and Psychiatry, 27, 1421-1435.

Hopkins, A. P. (1968). Experimental Neuropathy in the Baboon. M.D. (Med.) Thesis, University of London.

Hopkins, A. P., and Gilliatt, R. W. (1971). Motor and sensory nerve conduction velocity in the baboon: normal values and changes during acrylamide neuropathy. Journal of Neurology, Neurosurgery, and Psychiatry, 34, 415-426.

Kaeser, H. E., and Lambert, E. H. (1962). Nerve function studies in experimental polyneuritis. In Progress in Electromyography. Edited by $\mathrm{P}$. Pinelli, with the collaboration of F. Buchthal and F. Thiébaut. Electroencephalography and Clinical Neurophysiology, Suppl. 22, 29-35.

Landau, W. M. (1953). The duration of neuromuscular function after nerve section in man. Journal of Neurosurgery, 10, 64-68.

Lissák, K., Dempsey, E. W., and Rosenblueth, A. (1939). The failure of transmission of motor nerve impulses in the course of Wallerian degeneration. American Journal of Physiology, 128, 45-56.

McDonald, W. I. (1963). The effects of experimental demyelination on conduction in peripheral nerve: a histological and electrophysiological study. I. Clinical and histological observations. Brain, 86, 481-500.

Miledi, R., and Slater, C. R. (1970). On the degeneration of rat neuromuscular junctions after nerve section. Journal of Physiology, 207, 507-528.

Rosenblueth, A., and Dempsey, E. W. (1939). A study of Wallerian degeneration. American Journal of Physiology, 128, 19-30.

Thomas, P. K. (1955). Growth changes in the myelin sheath of peripheral nerve fibres in fish. Proceedings of the Royal Society. Series B, 143, 380-391.

Titeca, J. (1935). Étude des modifications fonctionnelles du nerf au cours de sa dégénérescence wallérienne. Archives Internationales de Physiologie, 41, 1-56. 